Meta

Journal des traducteurs

Translators' Journal

\title{
Le passé, le présent et l'avenir de la traduction au Cameroun
}

\section{Oumarou Mal Mazou}

Volume 60, numéro 2, août 2015

$60^{\mathrm{e}}$ anniversaire. Les horizons de la traduction : retour vers le futur

$60^{\text {th }}$ Anniversary. Translation's Horizons: Back to the Future

$60 \mathrm{mo}$ aniversario. Los horizontes de la traducción: regreso al futuro

URI : https://id.erudit.org/iderudit/1032905ar

DOI : https://doi.org/10.7202/1032905ar

Aller au sommaire du numéro

\section{Éditeur(s)}

Les Presses de l’Université de Montréal

ISSN

0026-0452 (imprimé)

1492-1421 (numérique)

Découvrir la revue

Citer ce document

Mal Mazou, O. (2015). Le passé, le présent et l'avenir de la traduction au

Cameroun. Meta, 60(2), 354-354. https://doi.org/10.7202/1032905ar 


\title{
Le passé, le présent et l'avenir de la traduction au Cameroun
}

\author{
Oumarou Mal Mazou \\ Université de Liège, Liège, Belgique \\ Rmazou@doct.ulg.ac.be
}

Le bilinguisme institutionnel édicté par la Constitution donne au Cameroun le privilège de côtoyer la traduction tous les jours, vu que les textes/discours officiels écrits/ dits dans une des deux langues officielles (français et anglais) doivent être traduits. Cela implique la formation de traducteurs/interprètes dans des universités et grandes écoles, d'abord à l'étranger au lendemain des indépendances, puis sur place avec la création d'une école de traduction au mileu des années 1980 dont l'objectif était de former de futurs traducteurs/interprètes pour l'administration publique. Cet objectif devient caduc avec l'arrêt de l'intégration systématique de ses diplômés en 1999. Mais, l'École supérieure des traducteurs et interprètes (ASTI) n'a pas pour autant changé de cap quant à ses programmes d'enseignement qui, avec la procédure d'admission, sont restés pratiquement les mêmes: accès par voie de concours national, formation axée plus sur la pratique que sur la théorie. Ainsi, bien que les nouvelles cuvées de traducteurs soient désormais destinées au marché national et international, l'ASTI ne tient pas encore compte de cette nouvelle réalité: pas de cours spécifiques qui préparent les futurs traducteurs à affronter les marchés (déontologie, la gestion des contrats). Entre-temps, des instituts privés comme l'ISTI de Yaoundé, ou encore des programmes comme celui de l'Université de Yaoundé I ont vu le jour et proposent également un parcours presque calqué sur celui de l'ASTI, à la différence que l'admission se fait sur étude de dossier. Pourtant, outre les deux langues officielles, environ 300 autres langues coexistent dans le pays et il y a nécessité de traduire, puis interpréter des textes religieux, médicaux, juridiques ou administratifs pour des populations souvent analphabètes. Cette réalité impose un voyage traductif entre les langues locales et les langues officielles au quotidien. Le présent travail se donne pour objectif de retracer l'évolution de la traduction au Cameroun depuis les indépendances jusqu'à nos jours, en vue de proposer des pistes de réflexion quant à son futur à partir des données et tendances actuelles tant endogènes qu'exogènes. Nous espérons ainsi contribuer à éclairer la lanterne des pouvoirs publics et de la communauté académique sur l'importance d'investir dans l'enseignement et la recherche de la traduction, dans un monde sans cesse en mutation.

Oumarou Mal Mazou est traducteur à l'Assemblée nationale du Cameroun. Il est actuellement candidat au doctorat de traductologie à l'Université de Liège en Belgique et ses travaux portent sur la traduction de l'humour dans la poésie peule du Cameroun. Il a fait plusieurs communications dans divers colloques et congrès internationaux sur la traduction, dont «Traduction et politique » à Liège (2015), le congrès annuel de l'ACT en 2014 à St Catharines (Canada). II a publié notamment le compte-rendu de l'ouvrage Études littéraires africaines.Traductions postcoloniales, en 2014 et en 2013, l'article «Analyse des stratégies de la traduction des injures du peul en français et en anglais », Actes du colloque 'Impliciter-impliciter' (sous presse). 